\title{
Sectoral Dynamics in the Determinants of Micro, Small and Medium Enterprises (MSMEs) Growth in Zimbabwe
}

\author{
Moses Chundu \\ Faculty of Business Management Sciences and Economics, University of Zimbabwe, Harare, Zimbabwe \\ Email:mtgjcc@gmail.com
}

How to cite this paper: Chundu, $M$. (2020). Sectoral Dynamics in the Determinants of Micro, Small and Medium Enterprises (MSMEs) Growth in Zimbabwe. American Journal of Industrial and Business Management, 10, 1271-1290. https://doi.org/10.4236/ajibm.2020.107085

Received: July 1, 2020

Accepted: July 21, 2020

Published: July 24, 2020

Copyright ( 2020 by author(s) and Scientific Research Publishing Inc. This work is licensed under the Creative Commons Attribution International License (CC BY 4.0).

http://creativecommons.org/licenses/by/4.0/

\begin{abstract}
The study sought to determine whether the sector in which an enterprise operates affects the impact of various determinants of Micro, Small and Medium Enterprises (MSMEs) growth in Zimbabwe. It used of 2012 Finscope national MSMEs survey data which was modeled using probit model on a sample size of 3222 with growth as the binary dependent variable. MSMEs were divided into four main sectors being Agriculture (A), Wholesale and Retail (WR), Manufacturing (M) and Others (O). The bulk of the variables exhibited similar behaviour as in the main aggregate model. However, owner characteristics being age of entrepreneur, gender and marital status, whilst insignificant determinants in the main model, they behaved differently when data were disaggregated by sector. The coefficient of AGE became significant in the manufacturing sector and other sectors, coefficient of GEN being significant in the wholesale and retailing sector whilst the coefficient of MS was significant in the agriculture sector. The implication for policy is that the demographics of the MSMEs need to be taken into consideration in coming up with policy interventions to grow the sector.
\end{abstract}

\section{Keywords}

MSMEs, Sectoral Policy, Growth Determinants, Zimbabwe

\section{Introduction and Background}

Globally, Micro, Small and Medium Enterprises (MSMEs) are becoming key players in the economies of nations and the wider eco-system of firms. In the context of the United Nations (UN) agenda, MSMEs help in the achievement of Sustainable Development Goals (SDGs) relating mainly to industrialisation, shared 
growth and decent work (OECD, 2017). MSMEs are central in job creation, including employment of low-skilled workers who tend to benefit through skills development in enterprise with contributions to total employment ranging from 30\% - 95\% (IFC, 2010).

In the OECD area, MSMEs predominantly account for approximately $99 \%$ of all firms, accounting for about $70 \%$ of jobs, generating between $50 \%$ and $60 \%$ of value addition (OECD, 2017). Most countries have between 97\% and 99\% of businesses being in the MSMEs category, with the exception of a few outliers mainly due to data accuracy issues. Contributions to GDP are difficult to account for given that a significant proportion of MSMEs, especially in developing countries, is in the informal sector. Contributions to GDP range from $12 \%$ to $60 \%$. This contribution increases significantly across all regions in the world when informal sector contribution is taken into account (IFC, 2010). Thus, MSMEs are the main players in the world economies; hence there is a need to understand them better in order to improve industrial policy efficiency and effectiveness.

With less than ten years remaining to the 2030 target for SDGs, issues of poverty reduction, inclusiveness (gender equity-goal No. 5 and reducing inequality-goal No. 10) and greening the economy (sustainable production goal No. 12) need to be accelerated. In economies where MSMEs are becoming the dominant economic players, to accommodate new players from the previously marginalised groups, it is imperative that these small firms are growing sustainably. The architecture of MSMEs sector in developing countries is such that women are the dominant players; hence promoting growth of MSMEs in itself enhances the achievement of equity and gender related goals.

Whilst their role in economic development is acknowledged, it is disturbing to note that most MSMEs either fail during the first year of existence, or remain very small for longer periods (OECD, 2017). Over the years, various interventions by the Government of Zimbabwe (GoZ) and non-state actors have assumed that access to finance has been the key determinant of MSMEs growth (Sachikonye \& Sibanda, 2016), though not backed by sufficient empirical evidence. The Finscope MSME Survey Zimbabwe 2012, however, cited the lack of accurate and reliable information about the sector being the main obstruction to the development of targeted and evidence-based strategies to promote MSMEs growth (Strassburg \& Khumalo, 2012).

A quick survey of the history of a number of MSMEs (Karedza, Nyamazana, Mpofu, \& Makurumidze, 2014; Chipangura \& Kaseke, 2012; Mudavanhu, Bindu, Chigusiwa, \& Muchabaiwa, 2011; Zindiye, 2008) points towards failure by MSMEs to leverage various subsidised financial support programs for growth. The Finscope data show a relatively young MSMEs sector with $71 \%$ of the businesses having been in operation for 5 years or less. This poor growth performance of the sector after years of quasi-fiscal interventions to support the MSMEs, seem to suggest that something more than just access to capital may explain this phenomenon. 
Given the high failure rate of MSMEs in Zimbabwe, as evidenced by a mere $8 \%$ surviving to maturity (Strassburg \& Khumalo, 2012), there is a need to understand the real determinants of MSMEs growth that policymakers may have been missing. Without this understanding, the hope of building the Zimbabwean economy anchored on a vibrant MSMEs sector remains a hollow dream. If the surviving businesses are broken further down, the bulk of them would qualify under the micro category by employment size and almost all businesses under micro category by capitalization/turnover. Thus, the majority of the surviving $8 \%$ are remaining micro in size suggesting little or no growth over time. The above statistics are worrisome for any serious government; $8 \%$ survival rate, 95\% not growing and 95\% remaining in the informal sector warrants an investigation of the determinants of their growth in Zimbabwe. The main objective of the study is, therefore, to investigate whether the sector in which an enterprise is in has a bearing on the key determinants of MSMEs growth and development in Zimbabwe with a view to guiding policy (OECD, 2017).

The rest of the paper is organised as follows. Section 2 gives a brief profile of the MSMEs sector in Zimbabwe followed by the review of literature. Section 4 gives the methodological background to the study, followed by presentation and discussion of estimation results. The paper concludes by giving a summary and policy implications of the study.

\section{Profile of MSMEs Sector in Zimbabwe}

To account for sectoral variations, the Finscope data was disaggregated by sector reflecting the following sample characteristics as presented in Table 1 . The sample was highly skewed in favour of agriculture, followed by trade (wholesale and retail) with a combined weight of $75.7 \%$ (being $41.2 \%$ plus $34.5 \%$ ), then the manufacturing sector at $9.5 \%$. All the other sectors were very small and all in single digit category, hence the decision to combine all the small sectors under the umbrella "Other".

The main productive sectors in Zimbabwe are agriculture, mining and manufacturing. The agriculture sector is made up of smallholder farmers and commercial

Table 1. Sectoral Composition of MSMEs in Zimbabwe.

\begin{tabular}{cccc}
\hline Sector & $\begin{array}{c}\text { \% Contribution } \\
\text { in Study Sample }\end{array}$ & $\begin{array}{c}\text { Sectoral Sample } \\
\text { Size (n) }\end{array}$ & $\begin{array}{c}\text { Missing observations } \\
\text { dropped }\end{array}$ \\
\hline Agriculture & 41.2 & 1322 & 4 \\
Wholesale \& Retailing & 34.5 & 1105 & 5 \\
Manufacturing & 9.5 & 307 & 0 \\
Other & 14.8 & 478 & 1
\end{tabular}

Source: Author's computations from Finscope Survey 2012 data.

${ }^{1}$ Included in "Other" are the following sectors: Mining (0.8\%), Energy (2.8\%), Transport (0.9\%), Accommodation (1.7\%), Arts, Culture \& Education (1.7\%) and Other Services (6.9\%), whose sample sizes individually were too small to form a meaningful unit of analysis on their own. 
farmers, the latter being in the minority. Activities cut across disciplines from animal husbandry (dominated by chicken growers) to market gardening especially for those in the peri-urban locations to growers of cash crops dominated by tobacco growers. The agricultural sector composition changed significantly since year 2000 following the Fast Track Land Reform program. This, resulted in a shift in dominance in most sub-sectors from large-scale commercial to smallholder sector (Lebert, 2006; Moyo, 2011). Thus, the bulk of the output is now being accounted for by the smallholder sector which happens to be largely informal. Mining is composed of large scale formal mining operations owned largely by foreign and government entities and the artisanal miners mainly in the gold and chrome sectors. Most artisanal miners are not organised and are unregulated as they operate illegally (Spiegel, 2015). Efforts to support them have not been very successful since in most cases, they mine illegally and do not want to take responsibility for the environmental damage arising from their activities.

The manufacturing sector, which was strongly vertically integrated with the primary sectors of agriculture and mining, has suffered decades of de-industrialisation. The decline, which was triggered by the structural adjustments program of the 1990s, has seen most of the large corporations close shop, giving rise to new dominant players in the form of MSME manufacturing entities. Most of these are owner-run while those who employ mainly family labour remain in the micro category, employing not more than 5 employees. The sector is well diversified with the majority in the furniture-making business and steel-fabrication. Competition from cheap imports, especially from China, in the face of high production costs has remained a challenge threatening viability of manufacturing MSMEs. The absence of capital to retool has also contributed to the high production costs attributed to the use of obsolete technology. The few large players have been victims of a dysfunctional monetary and exchange rate regime that has made accessing foreign currency for importing raw materials a nightmare. This, has seen capacity utilisation levels in industry fall to record lows in the recent past (CZI, 2019)2.

The trade sector comprise wholesaling and retailing. The wholesale market has been changing over the years with the line separating wholesaling and retailing getting thinner as most wholesalers and even manufacturers are giving direct access to the end consumer; more so given that a significant amount of manufacturing is now happening in the informal sector. The opening up of international borders to trade has resulted in a new form of retailing, sourcing goods from offshore producers and operating under the banner of cross border traders (ZNCC, 2017). This is a low capital and easy entry sector. It often requires basic literacy to be able to calculate basic profit and therefore, has minimum entry barriers related to education. The activities can take place anywhere from one's backyard to rented business premises making regulation rather cumbersome.

${ }^{2}$ The 2019 CZI Manufacturing Sector Survey, reported that industry's capacity utilisation fell by $11.8 \%$ to $36.4 \%$ in 2019 from $48.2 \%$ recorded in 2018 projected to decline further to $27 \%$ in 2020 . 


\section{Literature Review}

The study is theoretically grounded in Gilbrat's theory of the firm buttressed by Churchill-Lewis Stages Growth Model and Network Theory. The deterministic approaches incorporating resource based view and dynamic capability view (motivation perspective and strategic adaptation perspective and the configuration perspective) also guided the conceptual framework for the current study. Storey (1994) cited the challenges of comparability of studies given industry dynamics, environmental settings and methodological variations ${ }^{3}$. Wiklund (1998) also alluded to the same challenges noting that, it is common that the same or similar phenomena are often studied in isolated research projects using different concepts, models and methods with researchers rarely building on theories and models developed by others. The need for an empirical framework that encompasses more than one theory was emphasised.

A survey of literature shows bias towards MSMEs in developed markets where the market dynamics tend to vary significantly with that of developing countries especially sub-Sahara Africa (Storey, 1994). While more and more work is now focusing on Africa, there is still a long way to go to understand small firm growth dynamics in Africa. A few empirical studies in the Zimbabwean context (Karedza et al., 2014; Chipangura \& Kaseke, 2012; Mudavanhu et al., 2011; Zindiye, 2008), have tended to focus on obstacles to MSMEs growth and on why MSMEs have been failing over the years and mostly in selected sectors in specific geographic areas. This, tend to limit the applicability and generalisation of research findings. Doern (2009) gave a critic of the methodology of investigating barriers/obstacles to growth as an approach to understanding small firm growth dynamics arguing that studies in this context tell very little about why and how growth happens. The most common technique in the "barriers" approach is to present respondents with a list of potential constraints and ask them to indicate whether and to what extent they believe each item on the list is important to the growth of their businesses. It was further argued that respondents are usually influenced by popular opinion or what has become known as "barrier rhetoric" rather than personal experience. These studies fail to capture how the cited/perceived common barriers influence their growth intentions and behaviours.

Table 2 summarises empirical findings on determinants of small firm growth with the observed effect on firm growth given in parentheses. The choice of which ones to include in one's model is a function of the choice of theoretical framework and availability of data.

The empirical review pointed towards general consensus on the significance of the following small firm growth determinants; age of owner, education, training and prior management experience of the owner, motivation to be in business, size of the firm, legal status of the firm, location, level of regulation and taxation policy. The reviewed literature showed different approaches to studying

${ }^{3}$ These variations relate to choice of proxy for growth variable, sample size, and choice of reference time periods (Storey, 1994; Woldie, Leighton, \& Adesua, 2008). 
small firm growth and mixed results reflecting the heterogeneity of the MSMEs sector. This is largely because small firm growth has been studied from a multitude of perspectives (Wiklund, 1998). Delmar \& Davidsson (1998) contends that there is little agreement on what factors affect growth or even how growth is best measured. Part of the challenge being that most studies were cross-sectional and relied on relatively small samples, hence data limitations in general have led to fractional insights into the understanding of growth dynamics. Moreover, the few large sample empirical studies have failed to capture the heterogeneity of growth patterns due to data constraints.

On owner characteristics, Storey (1994) found no relationship between educational backgrounds and growth in nine of the 17 studies reviewed with some form of positive relationship in the other eight. The grading of educational qualifications is largely responsible for the mixed results as the measurement vary from country to country (Tuan \& Yoshi, 2009). Thus, the problem of heterogeneity in the sector needs to be considered when comparing different studies on firm growth. Many other studies (Chipangura \& Kaseke, 2012; Fatoki, 2011; Federico, Rabetino, \& Kantis, 2012; Karedza et al., 2014; Mambula, 2002) found owner characteristics of human capital and networks to be significant determinants of growth.

Few studies have focused on the significance of managerial and functional skills of the entrepreneur. In the case of Storey (1994), only two of the reviewed 18 studies focused on functional skills, finding these to be positively related to growth of firms. A related variable is training, which in the two studies reviewed showed no significance at all where an unskilled entrepreneur tries to acquire managerial and functional skills while in enterprise. Most of these studies relate to the developed world setting. However, even in a case studies of Nigeria, (Mambula, 2002; Okpara, 2011), Ghana (Yeboah, 2015), South Africa (Fatoki, 2011) and Zimbabwe (Mudavanhu et al., 2011), proprietors with business related

Table 2. Summary of factors influencing growth in small firms.

\begin{tabular}{|c|c|c|}
\hline The Entrepreneur/Resources & The firm & The Strategy/Environment \\
\hline 1. Motivation $( \pm)$ & 1. Age $( \pm)$ & 1. Workforce training $(+)$ \\
\hline 2. Education $(+)$ & 2. Sector & 2. Management training $(+)$ \\
\hline 3. Management experience $(+)$ & 3. Legal form $(+)$ & 3. Exporting $( \pm)$ \\
\hline 4. Functional skills $(+)$ & 4. Location & 4. Technology $(+)$ \\
\hline 5. Number of founders $(+)$ & 5. Size $( \pm)$ & 5. Social networks $(+)$ \\
\hline 6. Training $(+)$ & 6. Market adjustments $(+)$ & \\
\hline 7. Age $( \pm)$ & 7. Planning $(+)$ & \\
\hline 8. Prior sector experience $( \pm)$ & 8. New products $(+)$ & \\
\hline 9. Gender $( \pm)$ & 9. Information \& advice $(+)$ & \\
\hline \multicolumn{3}{|l|}{ 10. State support $(+)$} \\
\hline \multicolumn{3}{|l|}{ 11. Bureaucracy $(-)$} \\
\hline 12. Competition $(+)$ & & \\
\hline
\end{tabular}


qualifications tended to survive more than non-qualified proprietors, consistent with the findings in the developed world. Federico, Rabetino and Kantis (2012) found entrepreneurial human capital variables to be only relevant in Latin America and Mediterranean Europe. Thus, it would appear from these studies that it is not so much of training not being significant determinant of small firm growth but its timing. When acquired before getting into enterprise, training tends to have more significance compared to when it is acquired whilst in enterprise. This, is also consistent with the findings of Cooper and Gimeno-Gascon (1990) who found ten out of seventeen studies showing a positive relationship between prior level of education and business growth.

Findings on the impact of prior sector experience on the growth prospects of a small firm in developed countries are mixed, with numerous studies finding a non-existent or even a negative relationship between work experience and growth (Cooper, 1993; Storey, 1994). For instance, Storey (1994), found mixed results on the prior sector experience variable with five studies indicating no relationship between business growth and prior sector experience of the owner/manager whilst three studies showed that prior sector experience is associated with slower-growing firms, and one suggesting that prior sector experience is related to faster-growing firms. The problem of the "missing middle" arises from the absence of opportunities for relevant work experience in cases where structural unemployment is high. The variation in these findings was attributed to measurement problems as well as the samples used. Those who supported the positive influence of prior sector experience include (Federico, Rabetino, \& Kantis, 2012; Mbugua et al., 2013; Nichter \& Goldmark, 2009).

Interrogating the motivation for starting a business, the eight studies reviewed by Storey (1994) were divided but overall, found out that if the founder is unemployed prior to starting a business, that firm is unlikely to grow as rapidly as where the founder is employed, largely explained by leveraging the skills acquired in formal employment (Storey, 1994). This result was also confirmed by other studies (Sirec \& Mocnik, 2010; Strassburg \& Khumalo, 2012). According to the Finscope Survey 2012; 63\% of MSMEs owners cite unemployment/poverty/survival as the motivation to be in business. It is not surprising then, that $23 \%$ of the entrepreneurs said they would close their business if they were offered a job somewhere (Strassburg \& Khumalo, 2012). Empirical evidence on the effect of the age of the entrepreneur has shown that young entrepreneurs are most likely to start firms that grow largely because they have the energy, the necessary commitments and the motivation to do so compared to their older counterparts (Blackburn, Hart, \& Wainwright, 2013; Kangasharju, 1999; Storey, 1994; Woldie, Leighton, \& Adesua, 2008).

Social networks can also play an important role in helping entrepreneurs deal with environmental challenges. A study of entrepreneurs in the Ghanaian manufacturing sector supported this view as connections across different groups helped enhance mobility and to overcome regulatory or other obstacles (Nichter 
\& Goldmark, 2009). The Ghanaian story is true of most developing countries where networks have been found to help with innovation support associated with growth-enhancing opportunities (Rogerson, 2001). Other studies supporting this view include Havnes and Senneseth (2001) and Florin, Lubatkin and Schulze, (2003). Closer home in Zimbabwe, Strassburg and Khumalo (2012) came to a similar conclusion on the effectiveness of networks in promoting growth, especially in cases where experienced entrepreneurs in the network mentor and partner emerging ones.

On firm characteristics, the age of a firm is a widely used independent variable in the study of small firm growth. Storey (1994) found all the studies reviewed to be unanimous on the view that young firms tend to grow more rapidly than old ones. Storey (1994), however, cautioned that the results could have been influenced by the characteristics of the sample which was dominated by firms in start-up phase and therefore yet to fail. Results of studies by Almus and Nerlinger (2000) and Sleuwaegen \& Goedhuys (2002), also confirm this relationship that age is an important factor in determining business growth of MSMEs. This viewpoint has, however, been rejected by some researchers like Audretsch and Klepper (2000) who contrary to popular view, found that large technology firms in England tended to have higher growth prospects than their smaller counterparts.

Contrary to Gilbrat's law, Foreman-Peck, Makepeace and Morgan (2006) found that small firms tended to grow faster than large firms. The other studies that found firm size to be a significant determinant of firm growth, in the process rejecting Gilbrat's law, include (Delmar \& Davidsson, 1998; Hamilton \& Lawrence, 2001; Becchetti \& Trovato, 2002; Reichstein \& Dahl, 2004; Yasuda, 2005; Garnsey et al., 2006). Most of these studies came to the same conclusion on the significance of firm size, notwithstanding the varying definitions of firm growth used as dependant variable in the studies. Small firms have the advantage of being able to circumvent government regulations and taxation, an advantage not enjoyed by large firms, hence in some cases a disincentive to grow (Snodgrass \& Biggs, 1996). Jovanovic's (1982) learning model sees firms performing well in the initial stages with productivity increasing over time but slowing down as it grows towards its optimal size. However, some studies in developing countries found contrary results as firms suffer productivity losses as they become older due to failure to invest sufficiently in existing or emerging technologies (Woldie, Leighton, \& Adesua, 2008).

While study of UK and USA firms by Storey (1994) tend to reveal that limited liability companies had a higher failure rate than either sole proprietorship or partnerships, in the case of Zimbabwe it is not so much a choice of legal status but a choice of being registered or not being registered at all. The Finscope Survey revealed that in total, 85\% of all MSMEs in Zimbabwe are not registered/licensed at all and that of the $15 \%$ registered; only $17 \%$ of these are registered with the registrar of companies. It is not surprising then that the majority of the firms reported absence of growth over the survey period. Legal status of an enterprise therefore, affects growth prospects through influencing 
access to capital. Other studies that found legal status significant include studies by Olson and Bokor, (1995); Orser, Hogarth-scott and Riding, (2000); and Davidsson et al., (2002). There are, however, some isolated studies that found significant growth among sole proprietorship firms (Woldie, Leighton, \& Adesua, 2008). This finding is particularly significant in light of the redefinition of MSMEs in Zimbabwe that saw sole proprietors being included in the expanded definition of MSMEs. Their inclusion can influence the empirical results significantly to the extent they happen to be in the majority (Strassburg \& Khumalo, 2012).

On environment and strategy factors, empirical evidence points towards greater regulatory costs disproportionately forcing smaller firms out of business because they lack the turnover over which these fixed costs can be efficiently spread. This would be consistent with findings that MSMEs that perceive value added tax (VAT) compliance as most burdensome also experienced higher compliance costs (Foreman-Peck et al., 2006; Mungah, 2012). Whilst the operating environment has significant impact on business innovation and growth in general, it is acknowledged that young and old businesses are affected disproportionately with the young being more vulnerable, thus constraining growth and discouraging formalisation (OECD, 2017). "Furthermore, certain aspects of business taxation, including asymmetric treatment of profits and losses, the distribution of taxation between capital and labour income and the design of R\&D tax credits and incentives, can unintentionally disadvantage some young and small firms" (OECD, 2017: p. 15).

\section{Methodology}

\subsection{Data Sources}

This research made use of Finscope national survey data collected in $2012^{4}$, covering 923 variables across 3222 respondents in Zimbabwe. A nationally representative sample of small business owners was drawn, including those who were 18 years or older, those who perceived themselves to be business owners/generating an income through business activities and employing 75 people or less as well as entrepreneurs without any employees. The survey followed a multi-stage sampling process and comprehensive listing exercise (listing over 57,000 households in 500 Enumerator Areas, identifying 15,906 business owners). A total of 3222 face-to-face interviews were conducted by Research Continental Fonkom in September 2012. Given the challenge of obtaining large sample data on attitudes, perceptions and strategies, survey data becomes the most viable source (Sirec \& Mocnik, 2010). Okpara (2011), in a study of Nigerian MSMEs, also noted the difficulty of obtaining accurate financial information from respondents, hence collection of subjective financial information which is often more useful than objective one in such surveys.

${ }^{4}$ Finscope survey is the only comprehensive national survey on MSMEs done in Zimbabwe every 10 years, so the next available latest data will be in 2023. It would be an opportunity for a follow up validation study to see if the relationships exhibited here will still be holding. 


\subsection{Model Specification}

There seem to be no agreement on what is the best conceptual framework for analysing MSMEs growth dynamics. As a result, "the empirical results are very confusing" (McMahon, 1998: p. 4). Firm growth is complex, multifaceted phenomenon and heterogeneous in nature (Davidsson et al., 2005). The domains of psychology, sociology, and economics all seem to provide insight into a piece of the puzzle, but none explaining the phenomenon completely (Sirec \& Mocnik, 2010). Therefore, variants of existing models are the best to stay on the course of empirical discourse but also recognising country specific peculiarities which start from something as basic as the definition of the MSMEs to variations in the operating environment (Federico et al., 2012).

The model to be estimated contains thirteen specific independent variables and one binary dependent variable (growth as perceived by the owner). The explanatory variables covered owner characteristics, environmental characteristics and firm characteristics moderated by firm-specific contingent factors such as size, age and sector (Federico et al., 2012). Any empirical study investigating antecedents of business growth is to some extent reductionist in that it can examine only a fraction of the factors important for business growth (Gielnik, Zacher, \& Schmitt, 2017). Since the dependant variable is of a binary choice nature, the probit model was used as the model of analysis. Some of the explanatory variables like education and age are measured in ordinal numbers whilst the majority of the thirteen explanatory variables are measured as dummy variables. Probit Model analysis predicts based on probability using the cumulative normal to find the coefficients on the independent variables that maximize the probability of an outcome.

Guided by theoretical and empirical review and modelling by Storey (1994), and Tuan \& Yoshi (2009: p. 44) the model is specified as follows:

$$
\begin{aligned}
\text { GROWTH }_{i}= & a_{0}+\beta_{1} \mathrm{LF}_{i}+\beta_{2} \mathrm{PSE}_{i}+\beta_{3} \mathrm{ED}_{i}+\beta_{4} \mathrm{MOT}_{i}+\beta_{5} \mathrm{AGE}_{i} \\
& +\beta_{6} \mathrm{AGEF}_{i}+\beta_{7} \mathrm{EXP}_{i}+\beta_{8} \mathrm{BANK}_{i}+\beta_{9} \mathrm{GEN}_{i}+\beta_{10} \mathrm{MS}_{i} \\
& +\beta_{11} \mathrm{TEC}_{i}+\beta_{12} \mathrm{TAXP}_{i}+\beta_{13} \mathrm{SECj}_{i}+\varepsilon_{i}
\end{aligned}
$$

Equation (1) tests the significance of all the variables combined on growth where GROWTH $_{i}=$ growth of firm $i$ across all industries and the other variables as defined in Table 3. $\varepsilon_{i}=$ the error term or a random disturbance that is uncorrelated with the regressors and $\beta_{i}=$ the slope at mean showing the marginal effects of the variables on the dependent variable.

Since the survey covered the whole country, it is acknowledged that it can be a source of distortion in sampling given the anatomy of the sector which exhibit high degree of heterogeneity. Results from spatial studies and industry specific studies can potentially be different from aggregated results. "Nonetheless these problems are common to all empirical analysis on sample data" (Becchetti \& Trovato, 2002: p. 293). To deal with this potential challenge, the data was further disaggregated into four different sectors being; Agriculture (A), Wholesale and Retail (WR), Manufacturing (M) and Others (O). Equations (2)-(5) below model 
these sectoral growth estimates.

$$
\begin{aligned}
\text { GROWTH }_{i \mathrm{~A}}= & a_{0}+\beta_{1} \mathrm{LF}_{i}+\beta_{2} \mathrm{PSE}_{i}+\beta_{3} \mathrm{ED}_{i}+\beta_{4} \mathrm{MOT}_{i}+\beta_{5} \mathrm{AGE}_{i} \\
& +\beta_{6} \mathrm{AGEF}_{i}+\beta_{7} \mathrm{EXP}_{i}+\beta_{8} \mathrm{BANK}_{i}+\beta_{9} \mathrm{GEN}_{i}+\beta_{10} \mathrm{MS}_{i} \\
& +\beta_{11} \mathrm{TEC}_{i}+\beta_{12} \mathrm{TAXP}_{i}+\varepsilon_{i} \\
\mathrm{GROWTH}_{i W R}= & a_{0}+\beta_{1} \mathrm{LF}_{i}+\beta_{2} \mathrm{PSE}_{i}+\beta_{3} \mathrm{ED}_{i}+\beta_{4} \mathrm{MOT}_{i}+\beta_{5} \mathrm{AGE}_{i} \\
& +\beta_{6} \mathrm{AGEF}_{i}+\beta_{7} \mathrm{EXP}_{i}+\beta_{8} \mathrm{BANK}_{i}+\beta_{9} \mathrm{GEN}_{i}+\beta_{10} \mathrm{MS}_{i} \\
& +\beta_{11} \mathrm{TEC}_{i}+\beta_{12} \mathrm{TAXP}_{i}+\varepsilon_{i} \\
\mathrm{GROWTH}_{i M}= & a_{0}+\beta_{1} \mathrm{LF}_{i}+\beta_{2} \mathrm{PSE}_{i}+\beta_{3} \mathrm{ED}_{i}+\beta_{4} \mathrm{MOT}_{i}+\beta_{5} \mathrm{AGE}_{i} \\
& +\beta_{6} \mathrm{AGEF}_{i}+\beta_{7} \mathrm{EXP}_{i}+\beta_{8} \mathrm{BANK}_{i}+\beta_{9} \mathrm{GEN}_{i}+\beta_{10} \mathrm{MS}_{i} \\
& +\beta_{11} \mathrm{TEC}_{i}+\beta_{12} \mathrm{TAXP}_{i}+\varepsilon_{i} \\
\mathrm{GROWTH}_{i O}= & a_{0}+\beta_{1} \mathrm{LF}_{i}+\beta_{2} \mathrm{PSE}_{i}+\beta_{3} \mathrm{ED}_{i}+\beta_{4} \mathrm{MOT}_{i}+\beta_{5} \mathrm{AGE}_{i} \\
& +\beta_{6} \mathrm{AGEF}_{i}+\beta_{7} \mathrm{EXP}_{i}+\beta_{8} \mathrm{BANK}_{i}+\beta_{9} \mathrm{GEN}_{i}+\beta_{10} \mathrm{MS}_{i} \\
& +\beta_{11} \mathrm{TEC}_{i}+\beta_{12} \mathrm{TAXP}_{i}+\varepsilon_{i}
\end{aligned}
$$

In Equations (2)-(5), explanatory variables from the main model in Equation (1) were tested to see if they behaved differently in the various sectors as to exhibit sectoral peculiarities. Disaggregating helps to deal with the heterogeneity problem inherent in the MSMEs sector. Understanding the behaviour of specific sectors but from the national random sample helps present a more global picture which is a more accurate guide to policy making.

See Table 3 for the definition of variables used in the above models and their expected signs from literature.

Growth (GROWTH) is measured by a dummy variable from a qualitative

Table 3. Summary of explanatory variables \& expected signs.

\begin{tabular}{ccc}
\hline Variable Name & Variable Description & Expected Sign \\
\hline GROWTH & Dummy measuring whether a firm grew or not. \\
SECj & Sector dummy for sector j. \\
AGEF & Age of firm in years from the date firm was birthed. & - Legal form/status of the business. \\
LF & Motivation of entrepreneur for getting into business & + \\
MOT & Prior sector experience of the entrepreneur & + \\
PSE & Age of business owner in years. & + \\
AGE & Exports as a proxy for competitiveness. & + \\
EXP & Educational background of the entrepreneur \\
ED & measured by number of years of schooling. & + \\
TAXP & Tax payment measuring status of the firm. & + \\
BANK & Banking indicating whether a firm has a bank account. & + \\
GEN & Gender of the entrepreneur. & + \\
MS & Marital status of the entrepreneur. & + \\
TEC & Technology use. & + \\
\hline
\end{tabular}


question measuring how well a firm did in the year of reference compared to the previous year. Okpara (2011) also used this approach in a study of growth determinants in Nigeria, citing the difficulty of obtaining accurate quantitative data in Africa. This dummy variable works as a composite measure of firm growth given the controversies surrounding what should be the best measure of growth for empirical analysis purposes (Weinzimmer et al., 1998). Thus, the respondents were left to define growth whichever way they related with best, as long as they considered their businesses to have grown ${ }^{5}$ during the reference period.

\subsection{Estimation Procedure and Diagnostics Tests}

The data set was accessed in SPSS format in raw form and qualitative response (QR) models were employed. QR models apply in case of limited dependent variable (LDV) model where the dependent variable is an indicator of a discrete choice, such as a "yes" or "no" decision. In general, conventional regression methods are inappropriate in these cases (Greene, 2002). The method of estimation in this case is the maximum likelihood using the probit binary estimation procedure. Since the dependent variable is a binary variable (all values are 0 or 1) maximum likelihood estimates of the coefficients on independent variables are obtained via the Newton-Raphson method. As the model is nonlinear, the slopes $\beta \mathrm{i}$ depend on the values of the independent variables. By default the slopes with respect to each of the independent variables are calculated (at the means of those variables) (Cottrell \& Lucchetti, 2016).

For testing hypotheses about the coefficients, the likelihood ratio test was used, testing the null hypothesis that all the slope coefficients in the probit model are zero (Greene, 2002). One more curious characteristic of probit models is that estimation is not feasible if a model fits the data perfectly; this is called the perfect prediction problem. In such cases, the log-likelihood has no maximum, despite being bounded. The good thing is that Gretl, the program used for estimation has a mechanism for preventing the algorithm from iterating endlessly in search of a non-existent maximum. In the event that the perfect prediction problem is caused by a single variable, the program drops the offending variable automatically proceeding with estimation without it (Cottrell \& Lucchetti, 2016).

For the probit model, a conditional moment test on skewness and kurtosis is printed automatically as a test for normality (Cottrell \& Lucchetti, 2016). The test for normality, the log-likelihood ratio test and McFadden's pseudo-R-squared are automatically computed in Gretl. On the problem of omitted variables, if $X_{2}$ is incorrectly omitted from the model, i.e. $\beta_{2}^{*}$ is assumed incorrectly to be zero, then there are various asymptotic biases that may be computed, depending on the assumption on how the samples are being drawn. The effects on the standard errors of the estimate (derived from a misspecified model) are quite modest.

${ }^{5}$ The different measures include sales turnover, profitability, employment size and asset base. Thus, the size variable was dropped as an explanatory variable given that it is likely to be positively correlated with the dependant variable. 
Overall, the substantive results of probit analysis are quite robust and do not suffer much from the effects of omitted variables (Cramer, 2005).

\section{Presentation and Discussion of Results}

After running the main equation, Equation (1) was later estimated using subsamples by sector as classified in Table 1 in the form of Equations (2)-(5). The models (Equations (1)-(5)) performed well in terms of their predictive power, explaining on average $61 \%$ of the cases and passing the goodness of fit tests. The following tables, Table 4 and Table 5 give a summary of the probit results estimations, the former giving the coefficients and significance levels whilst the later presents the slopes as marginal effects.

There are sectoral variations in the results from the sectoral models showing varying degrees of effectiveness of determinants of growth across sectors as shown in Table 4 and Table 5. Education level of the entrepreneur (ED) is the only variable that exhibited robust effects across all sectors. Its coefficient highlighted in Table 4 carried the expected positive sign signifying that, regardless of the sector in which the firm is operating in, the higher the level of education of the owner/manager, the higher the chances of a small firm growing. The marginal effects, as shown in Table 5, were fairly significant across sectors ranging from $2 \%-10 \%$.

The ones whose coefficients were consistently insignificant include; a measure of tax compliance (TAXP), legal form (LF), exports (EXP) and technology (TEC).

Table 4. Summary of sectoral regression results; significant levels.

Dependent variable: GROWTH

\begin{tabular}{|c|c|c|c|c|c|c|c|c|c|c|}
\hline \multirow{2}{*}{$\begin{array}{r}\text { Table } \\
\text { Sector } \\
\text { Variable }\end{array}$} & \multicolumn{2}{|c|}{$\begin{array}{l}\text { Overall Model } \\
\text { Equation } 3.1\end{array}$} & \multicolumn{2}{|c|}{$\begin{array}{l}\text { Agriculture } \\
\text { Sector }\end{array}$} & \multicolumn{2}{|c|}{$\begin{array}{l}\text { Wholesale \& } \\
\text { Retail Sector }\end{array}$} & \multicolumn{2}{|c|}{$\begin{array}{c}\text { Manufacturing } \\
\text { Sector }\end{array}$} & \multicolumn{2}{|c|}{ Other Sectors } \\
\hline & LOS & Coeff & LOS & Coeff & LOS & Coeff & LOS & Coeff & LOS & Coeff \\
\hline LF & $\mathrm{N}$ & 0.0013 & NS & 0.0024 & S & - & NS & & NS & 21 \\
\hline PSE & * & & ** & & NS & & NS & & NS & -0.0029 \\
\hline $\mathrm{ED}$ & $* * *$ & 0.1036 & $* * *$ & 0.1410 & $* *$ & 0.0806 & * & 0.1022 & * & 0.0478 \\
\hline MOT & $* * *$ & 0.1734 & $* *$ & 0.1701 & $* *$ & 0.1779 & NS & 0.1812 & NS & 0.1667 \\
\hline AGE & NS & -0.0004 & NS & 0.0040 & NS & 0.0003 & $* * *$ & -0.0186 & $* *$ & -0.0083 \\
\hline AGEF & $* * *$ & -0 & $* * *$ & -0.0131 & $* *$ & -0.0150 & NS & 0.0023 & NS & -0.0129 \\
\hline EXP & NS & 0.1966 & N/A & & NS & 0.5210 & NS & 27 & NS & 11 \\
\hline BANK & * & & * & -0.2 & NS & 0.0152 & NS & & NS & -0.2298 \\
\hline GEN & NS & -0.0734 & NS & 0.0093 & * & -0.1706 & NS & -0.1190 & NS & -0.1170 \\
\hline MS & NS & -0.0123 & * & -0.1481 & NS & 0.0845 & NS & 0.1703 & NS & -0.0342 \\
\hline TEC & NS & 0.0534 & NS & 0.0786 & NS & -0.0341 & NS & 0.3625 & NS & 0.0444 \\
\hline TAXP & * & 0.3285 & NS & 0.4783 & NS & 0.5101 & NS & 0.2707 & NS & 0.2440 \\
\hline
\end{tabular}

${ }^{* *} p<0.01,{ }^{* *} p<0.05,{ }^{*} p<0.1$. NS $=$ Not significant; $\mathrm{N} / \mathrm{A}=$ Not applicable where variable was automatically excluded from the model. 
Table 5. Summary of sectoral regression results; marginal effects ${ }^{\mathrm{a}}$.

Dependent variable: GROWTH

\begin{tabular}{cccccccccccc}
\hline \multirow{2}{*}{$\begin{array}{c}\text { Sector } \\
\text { Variable }\end{array}$} & $\begin{array}{c}\text { Overall Model } \\
\text { Equation 1.1 }\end{array}$ & \multicolumn{2}{c}{$\begin{array}{c}\text { Agriculture } \\
\text { Sector }\end{array}$} & \multicolumn{2}{c}{$\begin{array}{c}\text { Wholesale \& } \\
\text { Retail Sector }\end{array}$} & $\begin{array}{c}\text { Manufacturing } \\
\text { Sector }\end{array}$ & \multicolumn{2}{c}{ Other Sectors } \\
\cline { 2 - 14 } & LOS & Slope & LOS & Slope & LOS & Slope & LOS & Slope & LOS & Slope \\
\hline PSE & $*$ & -0.0061 & $* *$ & -0.0121 & NS & + & NS & - & NS & - \\
ED & $* * *$ & +0.0173 & $* * *$ & +0.0553 & $* *$ & +0.0320 & $*$ & +0.0457 & $*$ & +0.0234 \\
MOT & $* * *$ & +0.0695 & $* *$ & +0.0670 & $* *$ & +0.0762 & & + & & + \\
AGE & NS & - & NS & + & NS & + & $* * *$ & -0.0065 & $* *$ & -0.0040 \\
AGEF & $* * *$ & -0.0049 & $* * *$ & -0.0051 & $* *$ & -0.0058 & NS & + & NS & - \\
EXP & NS & + & N/A & N/A & NS & + & NS & + & NS & \\
BANK & $*$ & -0.0482 & $*$ & -0.0775 & NS & + & NS & - & NS & - \\
GEN & NS & - & NS & + & $*$ & -0.0777 & NS & + & NS & - \\
MS & NS & - & $*$ & -0.0586 & NS & + & NS & + & NS & - \\
TEC & NS & + & NS & + & NS & - & NS & + & NS & + \\
TAXP & $*$ & 0.1330 & NS & + & NS & + & NS & + & NS & + \\
\hline
\end{tabular}

${ }^{* * *} p<0.01,{ }^{* *} p<0.05,{ }^{*} p<0.1$. ${ }^{a}$ Marginal effects are only summarised for those variables with statistically significant coefficients.

These variables were measured as dummies and given the skewed nature of the data, it is possible that meaning and significance could have been lost in the creation of the dummy variables. For instance, with a " 1 " for those who had paid tax the previous period and zero elsewhere and a "1" for those formally registered and a zero elsewhere, there were far too many " 1 " entries as the data revealed a less than $2 \%$ level of tax compliance and a less than $5 \%$ level of formalisation. Thus, abnormally high levels of tax avoidance and informality made it very difficult from the given data to establish a consistent pattern of the behaviour of sampled MSMEs.

Coming to non-outliers, it can be seen from the summary in Table 4 that motivation for getting into business (MOT) is a significant determinant, with its coefficient significant in the main model at the $1 \%$ level and also significant in two other sectors ${ }^{6}$ namely Agriculture and Wholesale \& Trade, both at $5 \%$ levels. The seemingly unexpected insignificance of MOT in the manufacturing sector could be attributed to the fact that the few (9.5\%) MSMEs in the manufacturing sector are mostly products of a failing formal industrial sector and a high degree of redundancy which force people into enterprise for survival, a choice one would probably not have made given the alternative of formal employment. Thus, the resultant dummy variable could have lost meaning as almost every respondent in this sector would indicate lack of deliberate motivation to be in business, hence it becomes difficult to establish causal relationship.

Age of the firm (AGEF) had a significant coefficient in the overall model as

${ }^{6}$ These two sectors constitute a combined $75.7 \%$ of the sample hence not surprising that the sectoral results on this variable are consistent with the ones from the main model. 
well as in agriculture and in wholesale and trade sectors but insignificant in manufacturing sector (where the sign was surprisingly positive). Thus, the conclusion in the main model, that young firms have better chances of growth compared to older ones, does not hold when it comes to the manufacturing sector. This is also consistent with the findings of Audretsch and Klepper, (2000) who contrary to popular view, found that large technology firms in England tended to have higher growth prospects than their smaller counterparts. There is need to understand the peculiarities in the Zimbabwean manufacturing sector accounting for the insignificance of this variable.

The coefficient of Age of the entrepreneur (AGE) was only significant in the manufacturing and other sectors at $1 \%$ and $5 \%$ levels respectively, carrying the expected negative sign in both cases. The reasons given in literature for the negative signs are more relevant in these two sectors that are fairly complex and challenging, requiring energetic and motivated drivers to grow; attributes that are more resident in young people. This is also consistent with findings of other studies in literature (Blackburn, Hart, \& Wainwright, 2013; Kangasharju, 1999; Storey, 1994; Woldie et al., 2008). Agriculture and trade tend to be fairly straightforward sectors where one doesn't have to be sophisticated to run them successfully.

The coefficient of the PSE variable had a negative sign and was significant at $10 \%$ level only in the agriculture sector whilst insignificant in all other sectors and also carrying the expected positive sign in the wholesale and retail sector. It would appear the dominance of the agriculture sector in the sample at $41.7 \%$ influenced the behaviour of the PSE variable in the main model. The nature of small scale agriculture is such that prior sector experience is not prevalent, hence the unexpected negative relationship with firm growth. The pattern and characteristics of the agriculture sector also explains the significance of the marital status (MS) variable as this sector has a fair balance of genders. The negative sign on the coefficient of the MS variable suggest that those not married had a better chance of growing their businesses. This, in part, is explained by the desire to succeed especially in single parents as a survival imperative. The gender variable (GEN) which had its coefficient insignificant in the overall model was significant at $10 \%$ level in the wholesale and retailing sector. The marginal effects on the positive coefficient sign suggest that females have a $7.7 \%$ higher chance of success and growing their enterprises compared to their male counterparts. This is not surprising given the fact that this sector is dominated by women in Zimbabwe who have mastered the industry over the years.

\section{Conclusion and Policy Implications}

The bulk of the variables exhibited similar behaviour as in the main overall model. However, owner characteristics being age of entrepreneur (AGE), gender (GEN) and marital status (MS), whilst insignificant determinants in the main model, they behaved differently when data were disaggregated by sector, with 
the coefficient of AGE becoming significant in the manufacturing sector and Other sectors, coefficient of GEN being significant in the wholesale and retailing sector whilst the coefficient of MS was significant in the agriculture sector.

Coefficient of age of the firm which was significant in the main model turned out to be insignificant in the manufacturing sector. Sectoral modelling revealed that age is a factor in the manufacturing sector, suggesting that support to the manufacturing sector MSMEs should favour those being run by young entrepreneurs as they have a higher chance of growing their enterprises than their older counterparts. Similarly, results for gender of the entrepreneur, which is generally insignificant in most studies including in the overall model, suggests that support to the wholesale and retail (trading) sector should be biased towards women who have a higher chance of growing their businesses than their male counterparts.

The implications for policy are that the demographics of the MSMEs need to be taken into consideration in coming up with policy interventions to grow the sector. Treating the sector as homogenous has catastrophic effects of policy failure. The significance of the educational background of the entrepreneur across all sectors points towards the need to innovatively attend to the capacity constraints of small firm owners. Whilst traditional approaches have focused on training the entrepreneur as a precondition for accessing loans, the results have not been encouraging. There is scope to come up with a model that recognises the need to capacity-build the entrepreneur, whilst acknowledging the limitations in the ability of the entrepreneur to assimilate new information and acquire new skills. This, will help overcome growth constraints associated with small firms.

The study has added to the literature on the behaviour of MSMEs in the context of a developing country using survey data. Given the heterogeneity of the sector, the findings presented here help shed more light on the dynamics of this rather complex phenomenon. As Sirec \& Mocnik (2010) argue, there can never be too many studies on the subject.

A follow up study using time series data for the post Zimdollar era and post hyperinflationary era (the period 2009-2018) could produce more reliable conclusions. The study could also have suffered from the survivorship bias as the sample studied is only those who had survived by the time of the survey and therefore cannot measure the growth dynamics of MSMEs which had failed. Incorporating in the sample MSMEs beyond the ones that survived could only be possible if it was time series data tracking the performance of the MSMEs over time. For future studies, given the volatility of the Zimbabwean operating environment, it would be useful to validate these findings using a different methodology on the next survey data expected in 2023. Also given the heterogeneous nature of the industry, the same methodology can be employed in other similar settings in other regions to see if the behaviour established in this study can be generalised for developing countries. A cross sectional study incorporating se- 
lected countries in the sub-Saharan region could prove useful.

\section{Acknowledgements}

Great appreciation goes to FinMark Trust for granting the author authority to use the FinScope Zimbabwe 2012 Small Business survey data for academic research purposes in his Ph.D. studies out of which this paper is derived.

\section{Conflicts of Interest}

The author declares no conflicts of interest regarding the publication of this paper.

\section{References}

Almus, M., \& Nerlinger, E. A. (2000). Testing “Gibrat's Law” for Young Firms-Empirical Results for West Germany. Small Business Economics, 15, 1-12. https://doi.org/10.1023/A:1026512005921

Audretsch, D., \& Klepper, S. (2000). Innovation, Evolution of Industry and Economic Growth.

Becchetti, L., \& Trovato, G. (2002). The Determinants of Growth for Small and Meduim Sized Firms. The Role of the Availability of External Finance. Small Business Economics, 19, 291-306. https://doi.org/10.1023/A:1019678429111

Blackburn, R. A., Hart, M., \& Wainwright, T. (2013). Small Business Performance: Business, Strategy and Owner-Manager Characteristics. Journal of Small Business and Enterprise Development, 20, 8-27. https://doi.org/10.1108/14626001311298394 http://www.emeraldinsight.com/doi/10.1108/14626001311298394

Chipangura, A., \& Kaseke, N. (2012). Growth Constraints of Small and Medium Enterprises (SMEs) at Glenview Furniture Complex (GFC) in Harare (Zimbabwe). International Journal of Marketing, 2, 39-83.

Cooper, A. C. (1993). Challenges in Predicting New Firm Performance. Journal of Business Venturing, 8, 241-253. https://doi.org/10.1016/0883-9026(93)90030-9 https://www.sciencedirect.com/science/article/pii/0883902693900309

Cooper, A. C., \& Gimeno-Gascon, F. J. (1990). Entrepreneurs, Processes of Founding and New Firm Performance. Institute for Research in the Behavioral, Economic, and Management Sciences.

Cottrell, A., \& Lucchetti, R. (2016). Gretl User's Guide: Gnu Regression, Econometrics and Time-Series Library.

Cramer, J. S. (2005). Omitted Variables and Mis-Specified Disturbances in the Logit Model. Tinbergen Institute Discussion Paper.

CZI (2019). Manufacturing Sector Survey 2019.

Davidsson, P., Achtenhagen, L., \& Naldi, L. (2005). Research on Small Firm Growth: A Review. 35th EISB Conference: Sustaining the Entrepreneurial Spirit over Time: Implications for Young Companies, Family Businesses, and Established Companies (pp. 1-27). IESE Business School.

Davidsson, P., Kirchhoff, B., Hatemi-J, A., \& Gustavsson, H. (2002). Empirical Analysis of Growth Factors Using Swedish. Journal of Small Business Management, 40, 332-349. https://doi.org/10.1111/1540-627X.00061

Delmar, F., \& Davidsson, P. (1998). A Taxonomy of High-Growth Firms. In Babson Col- 
lege-Kauffman Entrepreneurship Research Conference (PP. 1-13). Massachusetts, USA. https://fusionmx.babson.edu/entrep/fer/papers98/XIV/XIV_A/XIV_A.html

Doern, R. (2009). Investigating Barriers to SME Growth and Development in Transition Environments. International Small Business Journal: Researching Entrepreneurship, 27, 275-305. https://doi.org/10.1177/0266242609102275

Fatoki, O. O. (2011). The Impact of Human, Social and Financial Capital on the Performance of Small and Medium-Sized Enterprises (SMEs) in South Africa. Journal of Social Sciences, 29, 193-204. https://doi.org/10.1080/09718923.2011.11892970

Federico, J., Rabetino, R., \& Kantis, H. (2012). Comparing Young SMEs' Growth Determinants across Regions. Journal of Small Business and Enterprise Development, 19, 575-588. http://www.emeraldinsight.com/doi/10.1108/14626001211277406 https://doi.org/10.1108/14626001211277406

Florin, J., Lubatkin, M., \& Schulze, W. (2003). A Social Capital Model of High-Growth Ventures. The Academy of Management Journal, 46, 374-384. https://www.jstor.org/stable/30040630 https://doi.org/10.2307/30040630

Foreman-Peck, J., Makepeace, G., \& Morgan, B. (2006). Growth and Profitability of Small and Medium-Sized Enterprises: Some Welsh Evidence. Regional Studies, 40, 307-319. https://doi.org/10.1080/00343400600725160

Garnsey, E., Stam, E., \& Hefferman, P. (2006). New Firm Growth: Exploring Processes and Paths. Industry and Innovation, 13, 1-20. https://doi.org/10.1080/13662710500513367

Gielnik, M. M., Zacher, H., \& Schmitt, A. (2017). How Small Business Managers' Age and Focus on Opportunities Affect Business Growth: A Mediated Moderation Growth Model. Journal of Small Business Management, 55, 460-483. https://doi.org/10.1111/jsbm.12253

Greene, W. H. (2002). Econometric Analysis (5th ed.). Englewood Cliffs, NJ: Prentice Hall.

Hamilton, R. T., \& Lawrence, L. (2001). Explaining Size Differences in Smaller Firms. International Small Business Journal: Researching Entrepreneurship, 19, 49-60. https://doi.org/10.1177/0266242601192003

Havnes, P., \& Senneseth, K. (2001). A Panel Study of Firm Growth among SMEs in Networks. Small Business Economics, 16, 293-302. https://doi.org/10.1023/A:1011100510643

IFC (2010). Scaling-Up SME Access to Financial Services in the Developing World. In G20 Seoul Summit (pp. 1-144). Washington DC: World Bank Group.

Jovanovic, B. (1982). Selection and the Evolution of Industry. Econometrica: Journal of the Econometric Society, 50, 649-670. https://www.jstor.org/stable/1912606 https://doi.org/10.2307/1912606

Kangasharju, A. (1999). Growth of the Smallest: Determinants of Small Firm Growth. Pellervo Economic Research Institute Working Papers 21.

Karedza, G., Nyamazana, M. S., Mpofu, T., \& Makurumidze, S. (2014). An Analysis of the Obstacles to the Success of SMEs in Chinhoyi. European Journal of Business and Management, 6, 38-42. http://www.iiste.org

Lebert, T. (2006). An Introduction to Land and Agrarian Reform in Zimbabwe. https://books.google.com/books?hl=en\&lr=\&id=taHztaX28fcC\&oi=fnd\&pg=PA40\&dq =agrarian+reform +in+zimbabwe\&ots=n9KM8N5Esc\&sig=CMsshEnH3RdM7vYWFpx LNH5_rZ4

Mambula, C. (2002). Perceptions of SME Growth Constraints in Nigeria: University of 
Liverpool Library. Journal of Small Business Management, 40, 58-65.

http://eds.b.ebscohost.com.liverpool.idm.oclc.org/eds https://doi.org/10.1111/1540-627X.00039

Mbugua, J. K. et al. (2013). Factors Affecting the Growth of Micro and Small Enterprises: A Case of Tailoring and Dressmaking Enterprises in Eldoret. International Journal of Business and Social Science, 4, 285-293. https://pdfs.semanticscholar.org/98ec/952e042396c6d1126f953e713d56ca7f7bc6.pdf

McMahon, R. G. P. (1998). Stage Models of SME Growth Reconsidered. 98-5 Research Paper Series, Adelaide South.

Moyo, S. (2011). Three Decades of Agrarian Reform in Zimbabwe. Journal of Peasant Studies, 38, 493-531. https://doi.org/10.1080/03066150.2011.583642 https://www.tandfonline.com/action/journalInformation?journalCode=fjps20

Mudavanhu, V., Bindu, S., Chigusiwa, L., \& Muchabaiwa, L. (2011). Determinants of Small and Medium Enterprises Failure in Zimbabwe: A Case Study of Bindura. International Journal of Economy Research, 2, 82-89.

Mungah, R. G. (2012). Determinants of Growth of Manufacturing SMEs in Kenya: A Case Study of Industrial Area in Nairobi. Unpublished Ph.D. Thesis, D61/63047/2010, Nairobi: University of Nairobi.

Nichter, S., \& Goldmark, L. (2009). Small Firm Growth in Developing Countries. World Development, 37, 1453-1464. https://doi.org/10.1016/j.worlddev.2009.01.013

OECD (2017). Enhancing the Contributions of SMES in a Global and Digitalised Economy. In Meeting of the OECD Council at Ministerial Level (pp. 1-24). Paris: OECD Publishing. https://www.oecd.org/mcm/documents/C-MIN-2017-8-EN.pdf

Okpara, J. O. (2011). Factors Constraining the Growth and Survival of SMEs in Nigeria: Implications for Poverty Alleviation. Management Research Review, 34, 156-171. https://doi.org/10.1108/01409171111102786

Olson, P. D., \& Bokor, D. W. (1995). Strategy Process-Content Interaction: Effects on Growth Perf. Journal of small business management, 33, 34.

Orser, B. J., Hogarth-scott, S., \& Riding, A. L. (2000). Performance, Firm Size, and Management Problem Solving. Journal of Small Business Management, 38, 42-58.

Reichstein, T., \& Dahl, M. S. (2004). Are Firm Growth Rates Random? Analysing Patterns and Dependencies. International Review of Applied Economics, 18, 225-246. https://doi.org/10.1080/0269217042000186705

Rogerson, C. M. (2001). In Search of the African Miracle: Debates on Successful Small Enterprise Development in Africa. Habitat International, 25, 115-142.

http://linkinghub.elsevier.com/retrieve/pii/S0197397500000333 https://doi.org/10.1016/S0197-3975(00)00033-3

Sachikonye, S., \& Sibanda, M. (2016). An Assessment of Financing of SMEs in Zimbabwe by Commercial Banks. Acta Universitatis Danubius. Economica, 12, 213-224. http://journals.univ-danubius.ro/index.php/oeconomica/article/viewFile/3445/3733

Sirec, K., \& Mocnik, D. (2010). How Entrepreneurs' Personal Characteristics Affect SMES'Growth. Izvirni Znanstveni Članki.

Sleuwaegen, L., \& Goedhuys, M. (2002). Growth of Firms in Developing Countries, Evidence from Côte d'Ivoire. Journal of Development Economics, 68, 117-135. http://www.sciencedirect.com/science/article/pii/S0304387802000081 https://doi.org/10.1016/S0304-3878(02)00008-1

Snodgrass, D. R., \& Biggs, T. (1996). Industrialization and the Small Firm: Patterns and Policies. 
Spiegel, S. J. (2015). Shifting Formalization Policies and Recentralizing Power: The Case of Zimbabwe's Artisanal Gold Mining Sector. Society and Natural Resources, 28, 543-558. https://doi.org/10.1080/08941920.2015.1014606

Storey, D. J. (1994). Understanding the Small Business Sector. Abingdon-on-Thames: Routledge. https://www.taylorfrancis.com/books/9781315544335

Strassburg, S., \& Khumalo, J. (2012). Zimbabwe FinScope MSME Survey 2012. Johannesburg, South Africa.

http://documents.worldbank.org/curated/en/780081468137402417/Zimbabwe-FinScop e-MSME-survey-2012

Tuan, N., \& Yoshi, T. (2009). Factors Contributing to the Growth of Small and Medium Enterprises: An Empirical Analysis of Vietnam's Manufacturing Firms. Singapore Management Review, 31, 35-52.

Weinzimmer, L. G., Nystrom, P. C., \& Freeman, S. J. (1998). Measuring Organizational Growth: Issues, Consequences and Guidelines. Journal of Management, 24, 235-262. https://www.sciencedirect.com/science/article/pii/S0149206399800610 https://doi.org/10.1177/014920639802400205

Wiklund, J. (1998). Small Firm Growth and Performance Entrepreneurship and Beyond (pp. 1-361). Doctoral Thesis, Jönköping: Jönköping International Business School.

Woldie, A., Leighton, P., \& Adesua, A. (2008). Factors Influencing Small and Medium Enterprises (SMEs): An Exploratory Study of Owner/Manager and Firm Characteristics. Banks and Bank Systems, 3, 5-13.

https://repository.cardiffmet.ac.uk/handle/10369/2701

Yasuda, T. (2005). Firm Growth, Size, Age and Behavior in Japanese Manufacturing. Small Business Economics, 24, 1-15. https://doi.org/10.1007/s11187-005-7568-y

Yeboah, M. A. (2015). Determinants of SME Growth: An Empirical Perspective of SMES in the Cape Coast Metropolis, Ghana. The Journal of Business in Developing Nations, $14,1-31$

Zindiye, S. (2008). An Empirical Investigation into the Factors Affecting the Performance of Small and Medium Enterprises in the Manufacturing Sector of Harare, Zimbabwe. Alice: University of Fort Hare.

ZNCC (2017). Survey on Understanding the Dynamics and Characteristics of the Informal Sector in Zimbabwe. Harare. 